\title{
Complutum
}

ISSN: 1131-6993

\section{El vareo de bellotas: pervivencia de una técnica de recolección prehistórica en el bosque mediterráneo}

\author{
Enrique García Gómez ${ }^{1}$; Arturo Ruiz Taboada²; Juan Pereira Sieso ${ }^{3}$
}

Resumen. El vareo es una de las fases de la recolección de bellotas, frutos usados como alimento básico o como complemento de la dieta humana desde época prehistórica. Consiste en sacudir las ramas de la encina, u otras especies del género Quercus, sirviéndose de una vara de madera larga y flexible.

De esta herramienta no existen hasta el momento evidencias en el registro arqueológico debido a los materiales perecederos utilizados en su fabricación. Esta ausencia puede ser suplida con la información derivada tanto del estudio de la iconografía prehistórica e histórica como del registro etnográfico actual. En este artículo se analizan diversos ejemplos que van desde el Neolítico hasta la actualidad, que demuestran la pervivencia de esta milenaria práctica usada por las sociedades rurales de la Europa mediterránea.

Palabras clave: Recolección de bellotas; Neolítico; vareo; arte prehistórico; iconografía; etnografía.

[en] Knocking down acorns: the survival of prehistoric harvesting technique in the mediterranean forest

Abstract. The knocking down is one of the stages of acorn harvesting, used as a supplement to human diet from prehistoric times. It consists in shaking tree branches with the help of a long and flexible wooden pole.

Due to both the use of perishable materials, there is no evidence for this tool in the archaeological record. The lack of archaeological evidence for this practice can be compensated for with information derived both from the study of certain prehistoric art scenes and from the ethnographic record. Thus, the article analyses various examples, from Neolithic to current times, which show the endurance of this millenary practice, typical of agricultural societies in Mediterranean Europe.

Keywords: Acorn harvesting; Neolithic; "vareo"; prehistoric art; iconography; ethnography.

Sumario. 1. Introducción. Evidencias iconográficas en la prehistoria reciente. Arte rupestre. 2.1. La Sarga (Alcoy, Alicante). 2.2. Roca Benedí (Jaraba, Zaragoza). 2.3. Valonsadero (Soria). 3. Evidencia material en la prehistoria reciente. Neolítico, Edad del Cobre y Bronce. 4. Protohistoria y Edad Antigua. 5. Edad Media y Moderna. Evidencias documentales e iconográficas. 6. Una contrastación etnográfica en la provincia de Toledo. 7. Conclusiones. Bibliografía

Cómo citar: García Gómez, E.; Ruiz Taboada, A.; Pereira Sieso, J. (2020). El vareo de bellotas: pervivencia de una técnica de recolección prehistórica en el bosque mediterráneo. Complutum, 31 (1): 159-176.

\section{Introducción}

Desde el Neolítico asistimos a una especialización en la producción de alimentos, con la introducción progresiva de nuevas técnicas que harán de la agricultura y la ganadería la base de la subsistencia. No obstante, también se van a mantener prácticas propias de las comunidades cazadoras-recolectoras postglaciales, ya que abundantes testimonios indican la importancia que continuarán teniendo en sus estrategias la caza, la pesca, el marisqueo (Moure 1992: 15; García Gómez et al. 2002) y, sobre todo, la recolección de recursos vegetales silvestres (Zapata 2000). En el registro arqueológico

1 Diputación Provincial de Toledo. Centro Cultural San Clemente https://orcid.org/0000-0002-8841-6726

2 Universidad Complutense. arruiz01@ucm.es. Profesor Aranguren sn. Departamento de Prehistoria, Historia Antigua y Arqueología. Facultad de Geografía e Historia. Madrid 28040

https://orcid.org/0000-0002-7957-2954

3 Facultad de Humanidades de Toledo. UCLM.

https://orcid.org/0000-0003-1266-5360 
de los yacimientos neolíticos de la península ibérica se ha comprobado cómo junto con las evidencias de plantas cultivadas aparecen habitualmente, en porcentajes relevantes, restos correspondientes a vegetales silvestres. Las bellotas destacan entre estos recursos (Buxó 1997: 147; Buxó y Piqué 2008; Zapata 2000; Antolín y Jacomet 2015). Esta circunstancia es similar a la que se ha documentado en distintos territorios de Europa, donde las bellotas, procedentes de distintas especies del género Quercus, desempeñaron un importante papel como recurso alimenticio para los grupos neolíticos (Mason 1992: 43; Zapata, 2000).

En el proceso de aprovechamiento de las bellotas destinadas al consumo humano se pueden distinguir distintas fases: recolección, secado, almacenado, triturado/molienda, cocinado y consumo (Mason 1992: 63-72). La primera de estas actividades se basa tanto en la recogida directa, como en el vareo de los distintos árboles productores de bellotas. Para esto último se utilizan como herramientas principales varas de madera, largas y flexibles. Estas varas se usan para golpear las ramas de la encina, fundamentalmente, aunque también de otras especies productoras de bellotas como alcornoques o robles. El vareo aparece en los estudios etnográficos y antropológicos como una de las técnicas habituales empleadas para la recolección de este fruto en los principales territorios donde se ha documentado la importancia de su papel en la alimentación humana, como California (Heizer 1978). La investigación de las tribus aborígenes de este territorio nos permiten conocer algunas características del vareo practicado por estas comunidades. En el caso de la tribu Wintu los hombres trepaban a los árboles y sacudían las ramas o usaban palos con el extremo en forma de gancho (Lapena 1978: 338). Los Eastern Miwok y los Costanoan usaban varas rectas para golpear las ramas y tirar las bellotas al suelo (Levy 1978 a: 403; Levy 1978 b: 498).

Mason señala para el caso de California que la práctica del vareo podía representar algunos efectos negativos sobre los árboles (Mason 1992: 185) y la disponibilidad de cosechas para el futuro, por la fractura de ramas que se comparan con el efecto de una tormenta de granizo (Mason 1992: 65; Powers 1874). Sin embargo, los posibles efectos negativos, se ven compensados ampliamente, al valorar la rotura de ramas como una poda beneficiosa para el árbol y su futuro desarrollo (Mason 1992: 185). Los datos etnográficos muestran que el vareo es un proceso sencillo y eficaz para aumentar el rendimiento en la reco- lección, con la obtención de la totalidad de los frutos disponibles en el menor tiempo posible. El vareo permite acceder en un plazo muy corto de tiempo a toda la producción de bellotas de un árbol, sin esperar a la caída natural, que suele suceder a lo largo de varias semanas. Las bellotas que se pueden encontrar en el suelo durante un proceso de recolección que respete los plazos naturales no son ni numerosas ni apreciadas. En primer lugar, porque se convierten en el alimento de una gran cantidad de animales que las aprovechan e incluso almacenan. En segundo lugar porque su estado de conservación, por la humedad del suelo o por haber sido parasitadas, a veces no es el más idóneo para su consumo (Antolín 2016: 21).

Desde el punto de vista del registro arqueológico, tanto prehistórico como histórico, tenemos abundantes ejemplos que nos permiten reconstruir la cadena operativa de los distintos procesos y elementos implicados en el aprovechamiento de las bellotas para el consumo humano. Desde los silos y otras estructuras o recipientes para el almacenaje, los molinos y morteros para el triturado y molienda, los análisis de contenidos para el cocinado y los estudios de paleodieta y fitolitos para el consumo. Frente a este registro destaca la escasa o casi nula evidencia arqueológica de los elementos utilizados para la que sería la primera fase de esta cadena operativa, la recolección en general y el vareo en particular. Esto se deriva tanto por la simplicidad y facilidad de selección, reemplazo y reciclaje de los instrumentos utilizados, varas con un bajo nivel de manufactura o elaboración, como por los problemas de conservación que tiene la madera con la que se fabrican a lo largo del tiempo. Nos encontramos, pues, con la dificultad de documentar un instrumento de madera poco elaborado, que en caso de deterioro o pérdida de la funcionalidad inicial podía ser reutilizado en otra función y formato. A esta circunstancia habría que añadir que solo en circunstancias muy excepcionales podría conservarse en el registro arqueológico y ser interpretado en su función dentro de la cadena operativa del aprovechamiento de las bellotas.

Uno de los objetivos de este trabajo es identificar fuentes de información a las que podamos recurrir, dadas las dificultades objetivas para localizar elementos de cultura material que podamos identificar con el vareo. Desde una perspectiva etnoarqueológica, a partir de las evidencias antropológicas y etnográficas que nos permiten reconstruir la cadena operativa de la recolección de bellotas, pretendemos valorar una serie de evidencias de cultura material, iconográficas 
y documentales que podamos relacionar con la práctica del vareo. En este caso, el concepto de cadena operativa no está aplicado a un proceso de elaboración de una herramienta o elemento de cultura material. En el caso del vareo habría una cadena operativa específica, sobre la selección de la materia prima, elaboración uso y abandono para las varas utilizadas.

En el presente trabajo nuestra atención se dirige a la actividad inicial del proceso de aprovechamiento de la bellota. Dentro de la cadena operativa centramos nuestra atención en la recolección sistemática mediante el vareo. También queremos comprobar qué aspectos de esta técnica de recolección han pervivido en el ámbito peninsular a partir de su comparación con las evidencias etnográficas. La presentación de estas evidencias seguirá una estructura temporal desde la prehistoria reciente, que abarcaría desde el Neolítico a los inicios de la Edad del Hierro, pasando por la Protohistoria, Historia Antigua, Medieval y Moderna hasta la actualidad. Somos conscientes de la escasez de evidencias, para un espacio temporal tan amplio, pero al mismo tiempo creemos que las aportaciones son suficientemente significativas para el propósito de este trabajo.

\section{Evidencias iconográficas en la prehistoria reciente. Arte rupestre}

Las representaciones rupestres conocidas como Arte Levantino y que, en la actualidad, se denominan Arte Rupestre del Arco Mediterráneo, fueron valoradas durante largo tiempo como una de las manifestaciones de las comunidades de cazadores recolectores epipaleolíticos de la península ibérica. En la actualidad existe un cierto consenso en atribuir su autoría a las primeras comunidades neolíticas (Hernández Pérez y Martí Oliver 2000-1), cuyo inicio se puede remontar a la segunda mitad del VI milenio a. C. (Molina Balaguer et al. 2003). Entre los temas dominantes destacan las representaciones individuales o de pequeños grupos de cazadores, junto con la presencia de animales de alto contenido simbólico como los cérvidos y caprinos (Hernández Pérez y Martí Oliver 2000-1: 263). También aparecen, aunque escasas, escenas relacionadas con la recolección, como la recogida de miel de la Cueva de la Araña (Bicorp, Valencia) o escenas de recolección de frutos silvestres asociadas con el vareo (Fig. 1). Atendiendo al objetivo de este trabajo presentamos dos ejemplos pictóricos que ilustran sobre el proceso de recolección de frutos arbóreos, directamente relacionados con un posible vareo. Completamos estas evidencias con un ejemplo de un recurso, posiblemente relacionado con el vareo, encuadrado en el arte esquemático de cronología más tardía.

\section{1. La Sarga (Alcoy, Alicante)}

La primera de las escenas de recolección mediante vareo procede de La Sarga (Alcoy, Alicante), uno de los yacimientos más importantes del arte rupestre del arco mediterráneo, ya que en él se conservan representaciones pictóricas de los tres estilos de este arte: macroesquemático, levantino y esquemático.

Integrado por tres abrigos, en el primero de ellos se documentó un panel en el que aparecen varias figuras humanas, una de las cuales mira a dos árboles, cuyos frutos parecen caer y dispersarse por el suelo (Fig. 1). El brazo de la figura aparece asociado a un largo trazo lineal que atraviesa y sobrepasa el follaje de uno de los árboles (Hernández Pérez et al. 2002: 65-66). Para algunos investigadores se trata de una escena en la que se muestra la recolección de frutos mediante vareo (Fortea y Aura 1987) y proponen que los frutos recolectados podrían ser almendras. Señalar que el almendro fue introducido desde Asia por los fenicios en la península ibérica durante el primer milenio a. C. por lo que durante el Neolítico este tipo de cultivo todavía no se había desarrollado (Montero Riquelme, 1993) (Pérez, Jordá et al. 2017).

Una segunda línea de investigación basada en estudios paleoclimáticos, botánicos y cronoculturales ha propuesto una interpretación diferente. Los árboles podrían ser encinas o acebuches, por su copa compacta y globosa. El hecho de que cada ejemplar se represente con varios troncos puede ser característico de ambas especies. La multiplicidad de troncos en las encinas se genera, normalmente, cuando las condiciones ambientales son adversas, por lo que se reproducen mediante renuevos y rebrotes en vez de semillas. En estas condiciones poco favorables, sobre todo si las heladas son fuertes, el acebuche no es capaz de sobrevivir. Las características climatológicas de las tierras del interior de Alicante podrían corresponder con las reseñadas, por lo que se podría interpretar que en la escena pintada de $\mathrm{La}$ Sarga se están vareando bellotas. Esta interpretación se ve refrendada en el registro arqueológico por la presencia de bellotas en yacimientos neolíticos del término de Alcoy como La Falguera y Cova de Santa Marina (Pérez Jordá 2005; Buxó y Piqué 2008). 

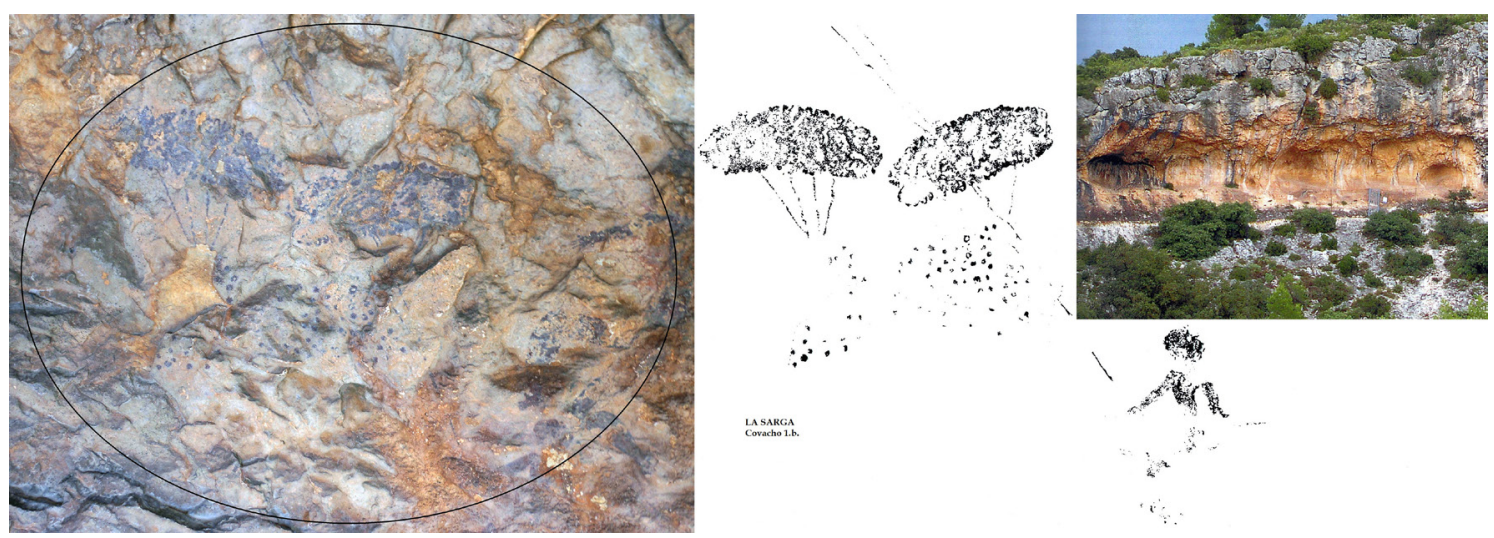

Fig. 1. Escena de vareo, covacho $1 \mathrm{~b}$ del abrigo de La Sarga (Alcoy, Alicante), según Hernández Pérez et al. 2002 y Fortea y Aura 1987.

\subsection{Roca Benedí (Jaraba, Zaragoza)}

La segunda representación de arte rupestre que podemos relacionar con el vareo procede de un abrigo de la cuenca del río Jalón. Este corredor natural de comunicación con la Meseta Sur amplía hacia el oeste el territorio de la península ibérica donde aparecen las manifestaciones del arte rupestre del arco mediterráneo (Utrilla et al. 2010). El lugar donde se localizaron las pinturas es un barranco del río Mesa, que recuerda por su topografía al Barranco de la Valltorta (Castellón), yacimiento clásico de este tipo de arte rupestre.
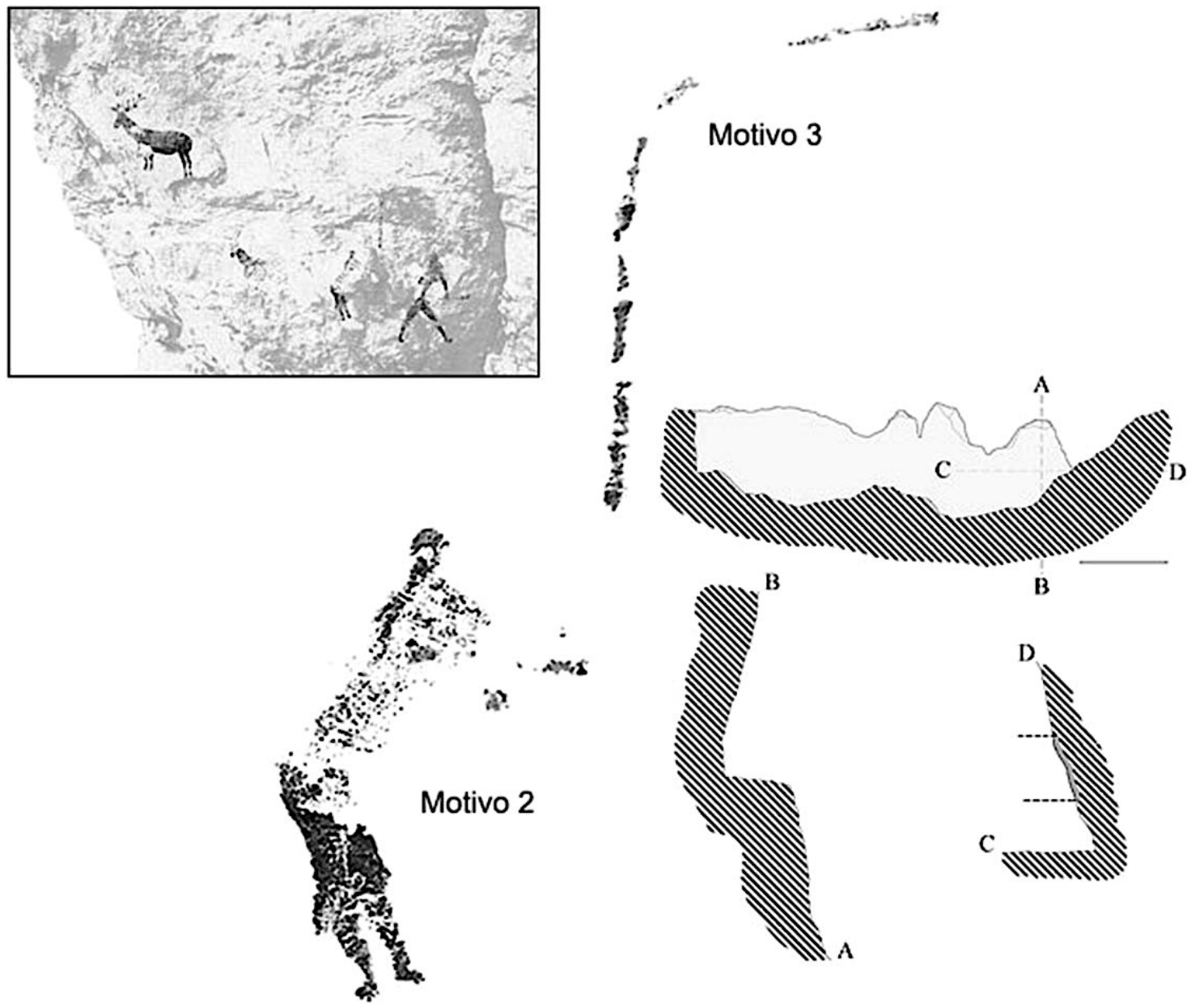

Fig. 2. Motivos 2 y 3 de Roca Benedí (Jaraba, Zaragoza), según Utrilla et al. 2010. 
El abrigo donde se documentaron las pinturas (Fig. 2) domina visualmente el meandro principal del barranco, a lo que hay que añadir la excelente acústica del anfiteatro natural que las rodea, que según los investigadores habría que poner en relación con su función de marcador territorial (Utrilla et al., 2010: 230). Para el propósito de nuestro trabajo destacamos entre los distintos motivos pintados $\operatorname{los} \mathrm{n}^{\circ}$ 2 y 3 (Fig. 2). El motivo $n^{\circ} 2$ se ha interpretado como una representación femenina inclinada hacia adelante, pintada en negro, sobre la que se reconoce la figura de un niño colocado sobre la espalda de la mujer. El motivo $n^{\circ} 3$, integrado por un trazo vertical que se va curvando $\mathrm{y}$ que, a pesar de que presenta interrupciones en algunos sectores por los desconchados de la roca soporte, pudo estar unido con los brazos de la figura femenina (Utrilla et al. 2010: 232$3)$. En nuestra interpretación, se trata de una larga vara de extremo curvado utilizada para recolectar cualquier tipo de frutos silvestres entre los que probablemente estarían las bellotas, dadas las condiciones climáticas del periodo Neolítico inicial y las características edafológicas ${ }^{4}$.

\section{3. Valonsadero (Soria)}

En el caso de uno de sus abrigos, la escena forma parte de un gran panel denominado "El Mirador". Aunque es difícil precisar la naturaleza exacta de la representación, la escena la compone una figura humana de 9 centímetros de altura con cinco puntos o discos consecutivos de 2,5 de diámetro que cae de lo que se ha interpretado como árbol, formando parte de una actividad relacionada con la recolección. Acción identificada tanto por el acto de arrojar una piedra contra el árbol como con la posterior caída inmediata de los frutos de este (Gómez Barrera 2005: 48). Aunque el tipo de fruto no se encuentra definido, la escena ilustra la actividad recolectora descrita en este artículo (Fig. 3).

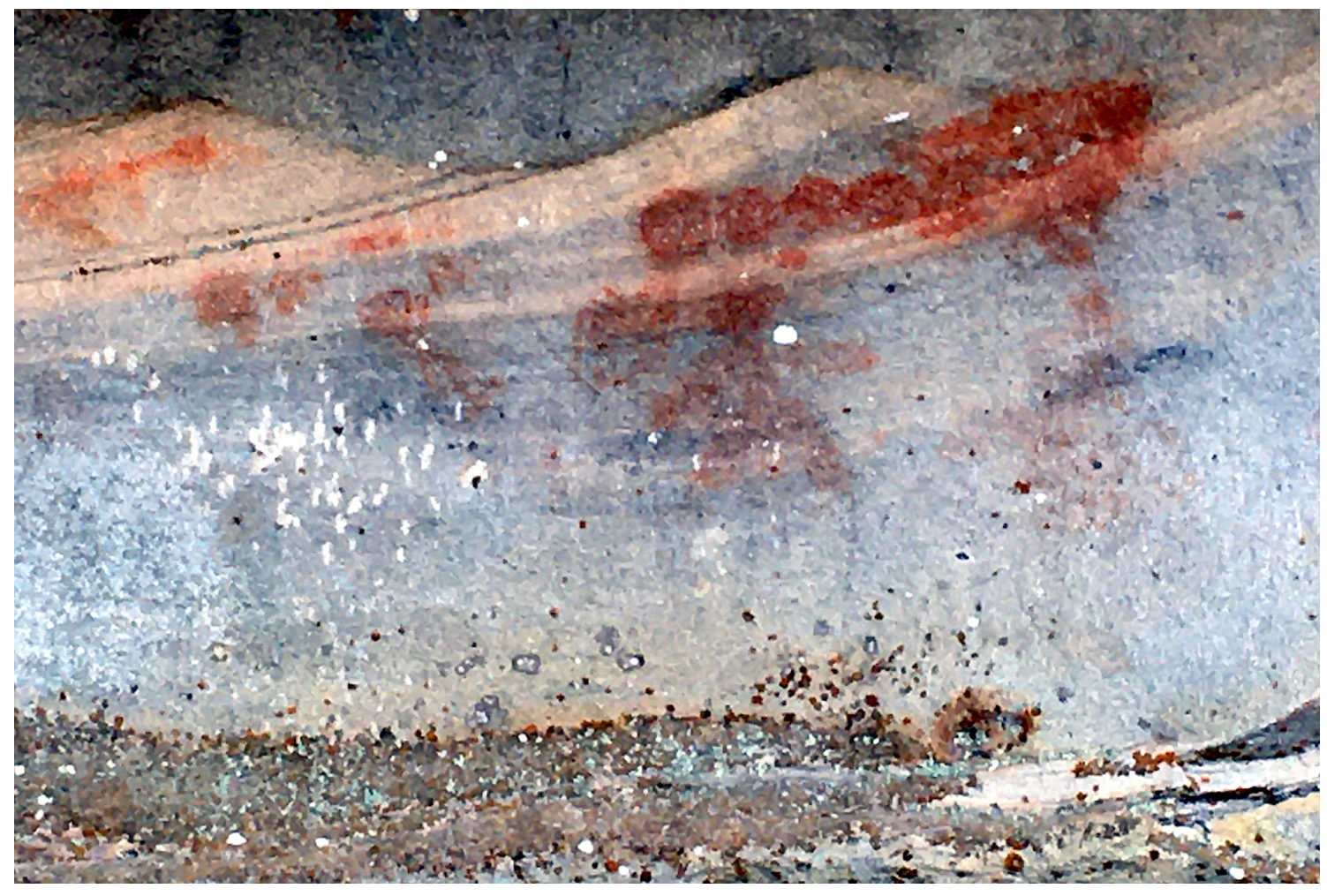

Fig. 3. Detalle del abrigo del Mirador en Valonsadero (Soria) en el que se reproduce una posible escena de recolección.

En resumen, que entre las minoritarias actividades de recolección representadas en el arte rupestre del arco mediterráneo aparezca el vareo, que interpretamos de bellotas, muestra la importancia que estas tenían en la alimentación de los grupos neolíticos de

En comunicación personal la autora Pilar Utrilla se mostró 
la península ibérica. Esta circunstancia se ve refrendada por el registro arqueológico documentado en más de medio centenar de yacimientos neolíticos (Fig. 4) en el que podemos identificar algunas de las fases de su procesado y consumo.

\section{Evidencia material en la prehistoria reciente. Neolítico, Edad del Cobre y Bronce}

Contamos en primer lugar con datos relativos al almacenaje de bellotas con distintas variantes, tanto en silos excavados en la roca en Ameal (Portugal) (Senna-Martínez 1994) como excavados en la tierra y forrados con placas de piedra, como en la Cueva de Nerja (Pellicer 1962; Muñoz 1970). También se almacenan en vasijas de cerámica mezcladas con otros frutos y semillas como en la Cueva del Toro (Martín Socas et al. 2004). El que aparezcan las bellotas mezcladas con frutos y semillas, tanto silvestres como cultivadas, es bastante frecuente. Están documentadas en yacimientos andaluces como Zuheros, Cueva del Toro y Nerja, pero sobre todo en los yacimientos de la fachada mediterránea: Cueva 120 en Sales de Llierca (Gerona) (Buxó 1987), Feix del Moro (Andorra) (Martín Colliga 1992), Cova de Les Cendres (Alicante) (Buxó 1997), Cova de L'Or (Martí y Juan-Cabanilles 1987), La Sarsa (Valencia) (López y Molero 1984) (Fig. 4).

Evidencias relacionadas con un posible tostado, una de las fases del procesado y consumo de este recurso, son las dos cubetas excavadas en la cueva de Chaves (Bastarás, Huesca) en las que se documentaron restos carbonizados de cotiledones de bellotas junto con cenizas y carbones propios de una zona de hogar/cocina, e incluso bellotas enteras que conservaban el pericarpio o cáscara (Zapata et al. 2008: 404). Estos restos, que la carbonización ha permitido su conservación y visibilidad en el registro arqueológico (Ruas y Bouby 2010), procederían de las pérdidas accidentales durante su tostado, o del último uso de las cubetas. El tostado no solo permite su conservación a medio-largo plazo, sino que también produce la eliminación del amargor que tienen ciertos tipos de bellotas y que impiden su consumo habitual en crudo. Esto último aparece citado no solo en las fuentes clásicas como Plinio, que refiere que la bellota en Hispania "tostada en- tre cenizas es más dulce" (García y Bellido 1978), sino también en la Edad Moderna, como señala Herrera en su Tratado de Agricultura en el capítulo dedicado a las encinas (Herrera 1996).

En el caso de la molienda y posterior consumo de la harina de bellotas los datos más significativos proceden del dolmen de Azután (Toledo) y del complejo funerario y habitacional de El Castillejo (Huecas, Toledo). Los análisis de fitolitos realizados tanto en los molinos procedente del asentamiento anterior a la construcción del dolmen como en las cabañas de El Castillejo, han confirmado la presencia de harina de bellota, en ocasiones mezclada con harina de trigo (Bueno et al. 2004: 63; Bueno et al. 2005). El consumo, último paso del aprovechamiento humano directo, está confirmado a partir de los análisis de paleodieta realizados a los restos humanos documentados en Azután y El Castillejo (Bueno et al. 2005). Los resultados confirman la presencia de la bellota en la dieta de las comunidades neolíticas del valle del Tajo.

La evidencia arqueológica reseñada muestra que durante el Neolítico, en diferentes territorios de la península ibérica, la recolección de las bellotas - un recurso abundante y disponible- fue una actividad integrada en las estrategias de las comunidades agrícolas como recurso estacional complementario, y que en ocasiones permitía afrontar situaciones de carestía alimentaria derivadas de malas cosechas. En los últimos años el significativo aumento de yacimientos neolíticos en los que se han encontrado restos de bellotas (Fig. 4) han contribuido a revalorizar el papel de las plantas silvestres en la gestión del territorio por los grupos neolíticos. Un sector de la investigación interpreta este registro arqueológico como el resultado de la explotación de territorios caracterizados por un paisaje adehesado (Bueno et al. 2004: 70; Bueno et al. 2005:86; López Sáez et al. 2007: 504). Otros investigadores no van tan lejos en la propuesta de identificar determinadas formas de paisaje, pero sí mantienen que el aprovechamiento de las masas forestales de encinar contribuiría de manera muy importante a la dieta de las comunidades neolíticas (Antolín y Jacomet 2015: 30). Este aprovechamiento sería particularmente importante en el NE peninsular durante el Neolítico antiguo y medio, asociado a un tipo de agricultura intensiva en campos permanentes (Antolín 2015: 35). 


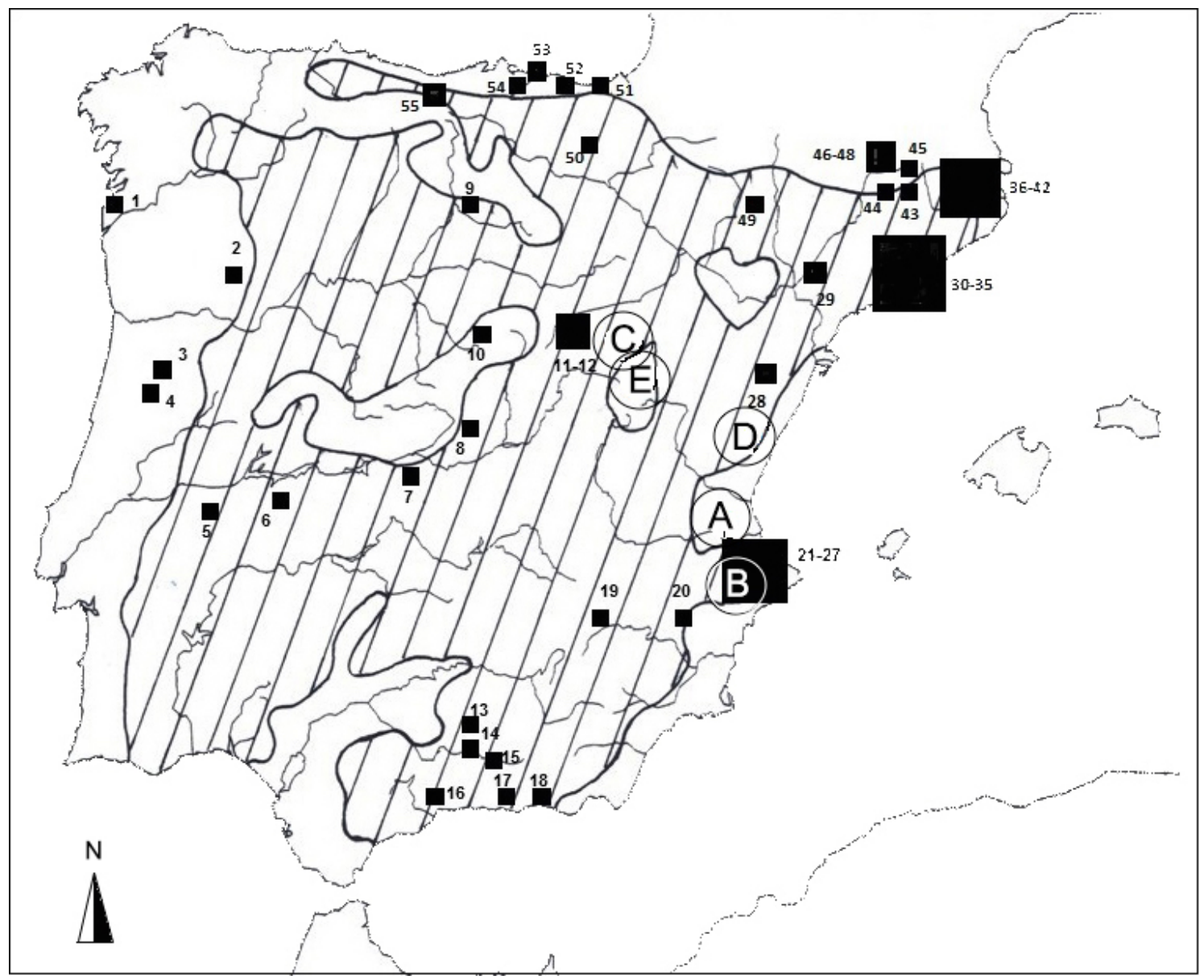

Fig. 4. Mapa con la distribución de la encina en la península ibérica -rayado-a partir de (Font de Quer 1954), localización de yacimientos neolíticos con hallazgos de bellotas a partir de (Pereira y García 2002) (Bueno et al. 2005) (Zapata et al. 2008) y relación de abrigos con pinturas rupestres mencionadas en el texto. 1 Chan do Cereixo (Gondomar, Pontevedra). 2 Buraco da Pala (Bragança, Portugal). 3 Ameal-IV; Oliveira do Conde (Beira Alta, Portugal). 4 Nelas (Mondego, Portugal). 5 Los Barruecos (Malpartida de Cáceres). 6 Dolmen Cabeçuda (Marvao, Portugal). 7 Azután (Toledo). 8 El Castillejo (Huecas, Toledo). 9 Quintanadueñas (Burgos). 10 Cueva de la Vaquera (Segovia). 11 Peña de la Abuela (Soria). 12 a La Revilla del Campo (Ambrona, Soria). 12 b La Lámpara (Ambrona, Soria). 13 Cueva de Los Murciélagos (Zuheros, Cordoba). 14 Cueva de los Mármoles (Cordoba). 15 Los Castillejos (Montefrío, Granada). 16 Cueva del Toro (Antequera, Malaga). 17 Cueva de Nerja (Granada). 18 Cueva de los Murciélagos (Albuñol, Granada). 19 Molino del Vadico (Yeste, Albacete). 20 Cueva de los Tiestos (Jumilla, Murcia). 21 Cova de les Cendres (Moraira, Alicante). 22 Mas d'Is (Penáguila, Alicante). 23 La Falguera (Alcoy, Alicante). 24 Cova de Santa Marina (Castell de Castells, Alcoy). 25 Cova de La Sarsa (Bocairente, Valencia). 26 Cova l'Or (Beniarres, Alicante). 27 Cova de la Recambra (Gandía, Valencia). 28 Cova Fosca (Ares del Maestre, Castellón). 29

Pla del Gardelo (Juneda, Lerida). 30 Cova de Sa Llorenc (Sitges, Barcelona). 31 Cova de Can Sadurní (Begues, Barcelona). 32 Pont Nou (Penedes, Barcelona). 33 Les Guixeres (Vilobi, Barcelona). 34 Cova del Frare (Barcelona). 35 Cova del Toll (Moia, Barcelona). 36 Cingle Vermell (Villanova de Sau, Barcelona).

37 Roc del Migdia (Vilanova de Sau, Barcelona). 38 Cova d'en Pau (Serinyá, Gerona). 39 La Draga (Bañolas, Gerona). 40 Plansallosa (Tortella, Gerona). 41 Bauma del Serrat del Pont (Tortella, Gerona). 42 Cova 120 (Sales de Llierca, Gerona). 43 Font del Rós (Berga, Barcelona). 44 Cova de les Portes (Lladurs, Lérida). 45 La Prunera (San Joan les Fonts, Gerona). 46 Feixa del Moro (Juberri, Andorra). 47 Balma de Margineda (Aixovall, Andorra). 48 Camp del Colomer (Juberri, Andorra) 49 Chaves (Bastarás, Huesca). 50 Kampanoste (Birgara, Álava). 51 Lumentxa (Lequeitio, Vizcaya). 52 Kobaederra (Kortezubi,Vizcaya). 53 Cueva de los Gitanos (Castro Urdiales, Cantabria). 54 Cueva El Mirón (Ramales de la Victoria, Cantabria). 55 Cueva de Arangas (Cabrales, Asturias). A, Cueva de la Araña (Valencia); B, La Sarga (Alicante); C, Abrigo Benedí (Zaragoza); D, Barranco de la Valltorta (Castellón); E, Valonsadero (Soria). 
La información disponible sobre el aprovechamiento de las bellotas durante la Edad del Cobre y del Bronce es igualmente significativa y puede considerarse representativa de la pervivencia de su consumo a partir de su amplia distribución por el territorio peninsular (Pereira y García Gómez 2002: 11-14; Alonso et al. 2016). Cabe destacar el hallazgo de bellotas en contextos rituales o funerarios como la Cueva Sagrada de Lorca (Murcia), fechada en la Edad del Cobre. En su interior se documentó un enterramiento infantil sobre una estera de esparto, acompañado de una túnica de lino y un plato de madera en el que se encontró una bellota y granos de uva (Ayala 1987: 11-14). En la Edad de Bronce cabe señalar la aparición de bellotas asociadas a los enterramientos de la Cueva del Fraile en Uclés (Cuenca) (Blasco 1997: 182-86). Sin embargo, a pesar del amplio registro de yacimientos en los que aparecen bellotas para estos períodos, no tenemos ningún indicio que nos permita asociarlos con el proceso de vareo.

\section{Protohistoria y Edad Antigua}

Para este periodo seguimos contando con todo tipo de evidencias que confirman la importancia de las bellotas como un recurso alimenticio en la península ibérica desde mediados del primer milenio a. C. hasta época visogoda (Pereira y García Gómez 2002) (Sanz et al. 2003: 243). Toda una serie de elementos de cultura material, evidencias arqueobotánicas y análisis de paleodieta nos ilustran sobre el proceso de recolección, almacenaje, procesado y consumo de las bellotas (Pereira 2010). Sin embargo, al igual que en la prehistoria reciente y por las mismas razones, carecemos de evidencias materiales sobre los artefactos relacionados con el vareo de los árboles. Debemos recurrir de nuevo al registro iconográfico, en este caso procedente del ámbito mediterráneo. La imagen que nos permite reconstruir las tareas relacionadas con el vareo de encinas procede de un ánfora de figuras negras procedente de Vulci (Italia), una de las más importantes ciudadesestado de la cultura etrusca. Esta pieza, conservada en el British Museum, fechada en el 520 a. C. y atribuida al pintor de Antímenes (Beazley 1986: 74) permite acercarnos a una verosímil reconstrucción del vareo. En una de sus caras se presenta una escena de recolección de aceitunas con tres olivos (Fig. 5), al mayor de los cuales, situado en el centro de la escena, se ha subido un adolescente que golpea sus ramas superiores con una vara de mediana longitud. Desde el suelo dos hombres adultos golpean las ramas con dos largas varas mientras otro adolescente recoge las aceitunas del suelo y las deposita en el interior de una cesta de asa vertical.

A pesar de que se trata de una escena que se enmarca en las labores agrícolas típicas de la agricultura mediterránea, como es el cultivo del olivo, en nuestra opinión la imagen del ánfora de Vulci documenta perfectamente las tareas implicadas en el vareo de otras especies arbóreas de abundante fructificación, como los Quercus. Se comprueba la pervivencia de una técnica propia de una economía recolectora adaptada, probablemente sin grandes cambios, a la economía agropecuaria mediterránea de la Segunda Edad del Hierro.

La información que nos proporciona el ánfora de Vulci sobre la organización de las labores relacionadas con el vareo se ve confirmada por las evidencias relacionadas con el resultado de su utilización: el volumen de cosecha obtenido. Los datos sobre el resultado de este sistema de recolección proceden del estudio de las bellotas que se documentan en yacimientos de la Segunda Edad del Hierro peninsular. Entre estos yacimientos cabe destacar el edificio monumental de La Mata (Campanario, Badajoz) (Rodríguez y Ortiz 2004) en el que los restos de bellotas encontrados han permitido reconstruir aspectos importantes de los procesos de recolección, almacenamiento y procesado de estas. En concreto, los abundantes restos de bellotas documentados en las estancias 1, 2 y 3 del edificio de La Mata han permitido identificar la especie, Quercus ilex subsp. ballota, lo que se interpreta como una recolección selectiva del fruto más dulce y digestible. Además, se pudo precisar que tanto la recolección como el secado de las bellotas se realizó al comienzo de su proceso de maduración (Vázquez et al. 2004: 431-432). Esta precisión sobre el corto periodo de tiempo en el que se realizó la recolección la asociamos a las ventajas de rentabilidad de tiempo y trabajo empleado en el vareo. Como hemos visto, esta actividad permite obtener la mayoría de la cosecha del árbol en un corto espacio de tiempo y no a lo largo de su periodo de maduración y caída natural, con las desventajas e inconvenientes que esto conllevaría. 

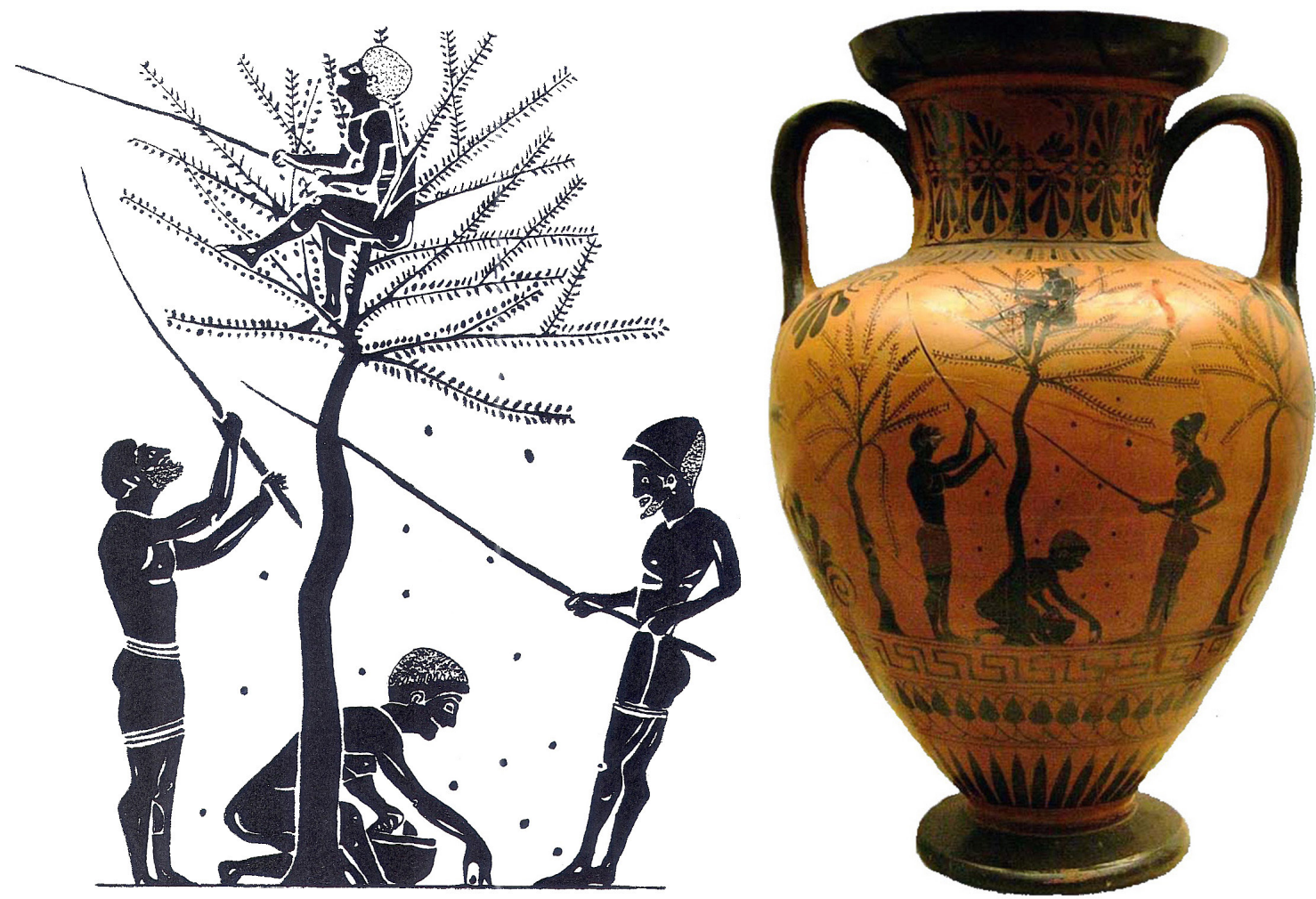

Fig. 5. Detalle de la cara A del ánfora de Vulci. Escena de vareo y recolección de aceitunas. Pintor de Antímenes. Vulci (Viterbo, Italia). S. VI a. C. British Museum B, 226.

\section{Edad Media y Moderna. Evidencias do- cumentales e iconográficas}

Restos arqueológicos, inscripciones, monedas, obras literarias, leyes civiles, cánones conciliares, crónicas, etc., suministran al historiador materiales y noticias varias para reconstruir la relación del ser humano con el bosque durante la Edad Media. Son numerosas las noticias del periodo de la Reconquista, estrechamente vinculado a la repoblación, a partir de las cartas-puebla y los fueros, que no eran otra cosa que un contrato agrario colectivo. En algunos de estos fueros, como el de Cuenca, dado por Alfonso VIII en 1189, la multa por cortar una encina por las bellotas es la misma que por un árbol frutal (Ureña 2003).

En la Baja Edad Media, plenamente asentado ya el régimen municipal, los concejos regularon las diversas actividades en el ámbito de su jurisdicción por medio de ordenanzas, para preservar las propiedades comunales y los bienes de propios concejiles, muchos de los cuales no eran sino montes y dehesas. No faltan las referencias escritas sobre prohibiciones y castigos para los que cogen las bellotas antes de que el concejo lo autorice, o en mayor can- tidad de la permitida. En otros casos también está prohibido varear las encinas para el pasto de los animales, por lo que parece evidente que los frutos recogidos estaban destinados al consumo doméstico (García Gómez et al. 2003: 14).

Una vez más destaca la ausencia de restos materiales sobre el vareo, por lo que debemos recurrir a las abundantes referencias iconográficas sobre el aprovechamiento que las comunidades campesinas hacían del bosque en general y de las especies del género Quercus y sus bellotas en particular. La mayoría de estas imágenes proceden tanto de la decoración de tímpanos y vidrieras de iglesias como de ilustraciones de libros de horas, en los que a modo de calendario el discurrir de los meses y estaciones se ilustran con escenas de las diferentes tareas agrarias a lo largo del año. Dos tipos de ilustraciones referentes al vareo de bellotas suelen aparecer en este tipo de calendarios, que suelen identificar como la mejor época para el aprovechamiento de las bellotas con el mes de noviembre o la estación del otoño. La más habitual de estas ilustraciones es la que presenta el vareo realizado para alimentar al ganado de cerda, que en la tempora- 
da anterior a su sacrificio reciben un engorde suplementario a base de bellotas consumidas en el monte. Una de las imágenes que ilustra este proceso procede de un manuscrito que se guarda en la biblioteca del monasterio de El
Escorial (Miranda García 2001), que pertenece a este primer tipo de imágenes en la que el porquero encargado de las piaras de cerdos golpea las encinas o robles con una larga vara (Fig. 6).

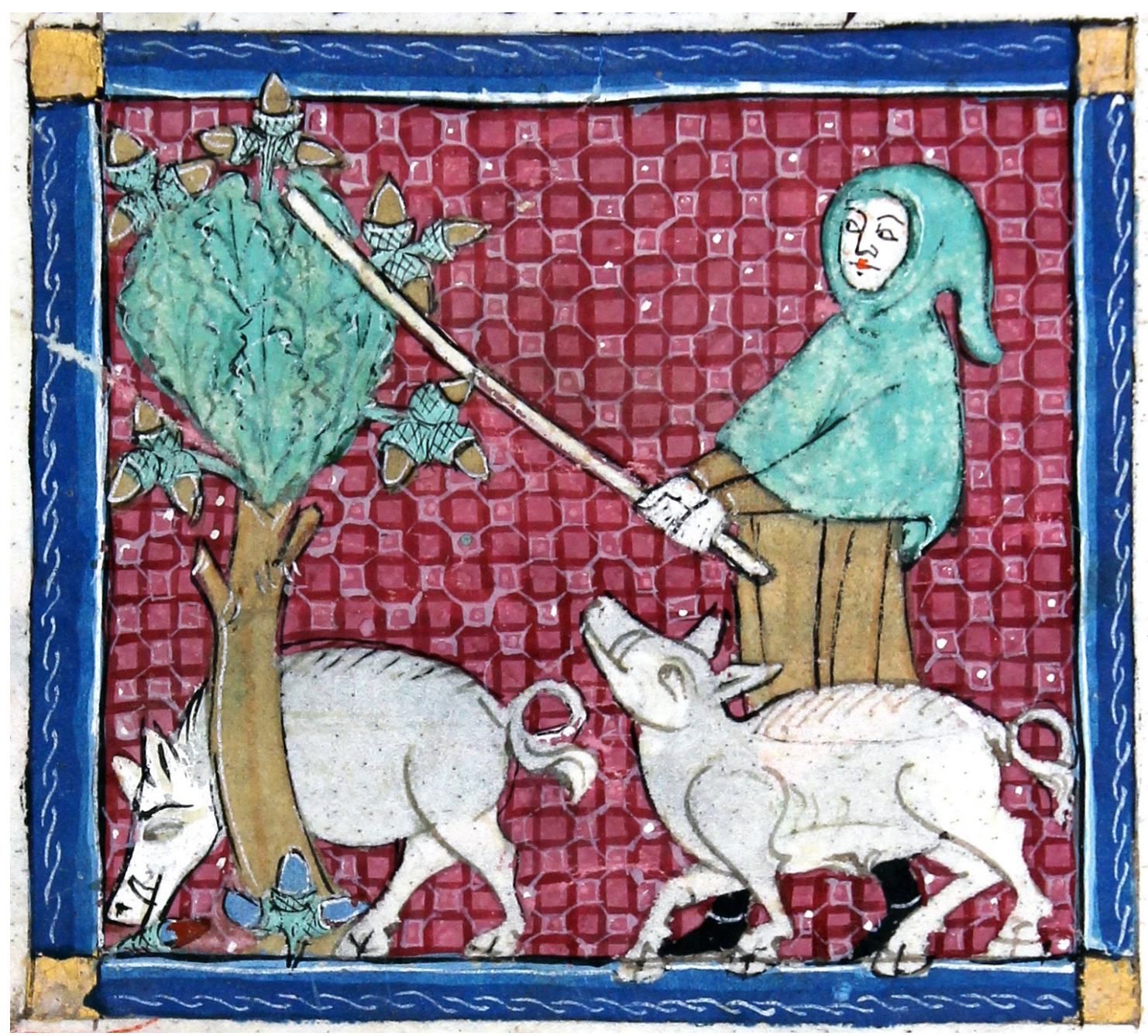

Fig. 6. Mes de noviembre. Siglo XIV. El Escorial Fol. 59 V Noviembre. Recolectando bellotas. Maestro Ermengaut (1322). Copyright (C) Patrimonio Nacional

La segunda imagen, menos habitual, procede de un libro de horas francés que se encuentra en la Biblioteca del Museo Morgan de Nueva York (Book of hours 1430: Ms M.64 fol.11v.). En la imagen se presenta la recolección de bellotas durante el mes de noviembre mediante vareo, en el marco de un aprovechamiento como alimento tanto para el ganado como para las personas (Fig. 7). Es particularmente destacable en esta imagen, que se fecha en 1430, en la transición de la Edad Media a la Moderna, comprobar cómo se mantienen las mismas estrategias y técnicas de recolección que veíamos en el ánfora de Vulci del siglo VI a. C. (Fig. 5). Como proponíamos en la interpretación de la escena de recolección de aceitunas, es indiferente si se trata de recoger la cosecha de una especie domesticada o no, lo pertinente es el uso de una estrategia que permita recoger la cosecha con la mayor eficacia, en este caso el vareo. En la imagen del manuscrito del Museo Morgan vemos dos personajes que realizan el vareo con largas varas desde el exterior de la encina o roble, y otro personaje, un niño o un adolescente, que sube 
al árbol para varear las bellotas desde el interior. Las bellotas vareadas son aprovechadas tanto por la piara de cerdos como por un personaje femenino, que las recoge usando una cesta de asa vertical, semejante a la documentada en el ánfora de Vulci.

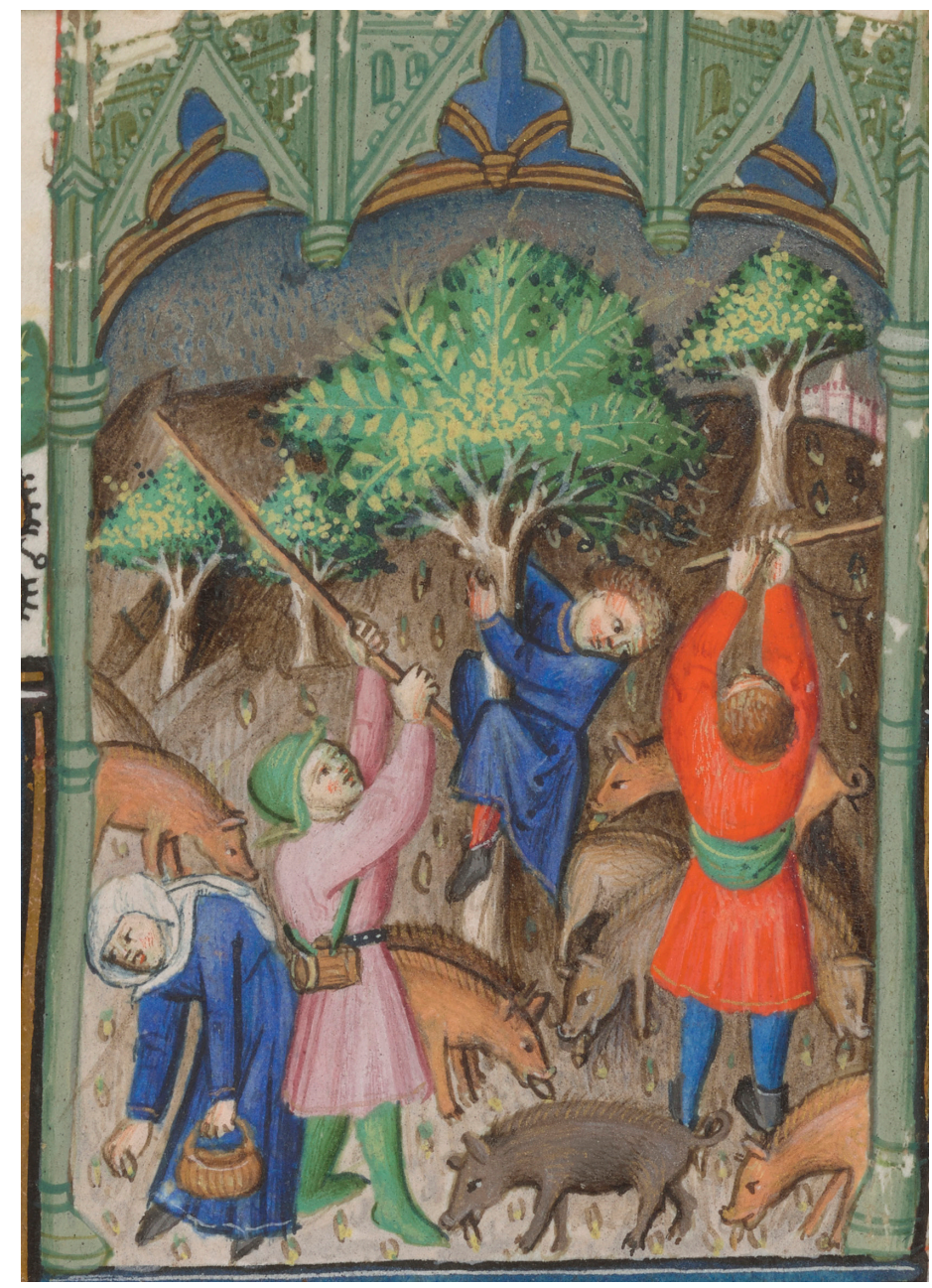

Fig. 7. Recolección de bellotas durante el mes de noviembre mediante vareo. Book of hours

(1430) Ms M.64 fol. 11 v. Copyright (C) Biblioteca del Museo Morgan de Nueva York

En la Edad Moderna los interrogatorios, como un nuevo tipo de fuente de información, vienen a unirse a las anteriores para obtener datos sobre el aprovechamiento de las masas forestales por parte de las comunidades rurales. Felipe II ordenó la primera de estas encuestas en 1575, con el objeto de componer una "Descripción e Historia de los pueblos de España" que nunca se realizó (Campos 2003). Otro objetivo perseguía el interrogatorio del Catastro de Ensenada, que en varias preguntas $\left(n^{\circ} 4,6,7\right.$, 11 y 12) se solicita información sobre el monte, la variedad de sus árboles y frutos, su producción y su valoración económica (Camarero 2002). La culminación de este tipo de trabajos realizados por medio de cuestionarios y corresponsales fue el Diccionario de Pascual Madoz, publicado entre 1845 y 1850 , que aunaba datos históricos, geográficos y estadísticos (Madoz 1987). Pero para entonces ya habían comenzado a producirse los cambios estructurales que conducirán a la desaparición del modo de vida tradicional en las zonas de monte mediterráneo. Durante el reinado de Carlos IV se ordenó la primera desamortización, a la que seguirían la frustrada del trienio constitucional y, ya con los liberales en el poder, la de los bienes de las órdenes religiosas en 1836, y la de las tierras concejiles, en 1855. Como consecuencia, muchos campesinos perderán los aprovechamientos comunales, entre ellos las bellotas, y además los nuevos propietarios modificarán el uso del encinar, lo que acarreará su destrucción en amplias zonas (García Gómez et al. 2003: 14). Los 
encinares que sobreviven a este intenso proceso de tala mantendrán su importante función en los sistemas tradicionales de organización del espacio agrario. El aprovechamiento de bellotas se mantendrá como una labor estacional, realizada por lo general de modo colectivo, cuyos resultados se dividen en partes iguales, distinguiendo la que va a destinarse como pienso para el ganado, de la que se destina para el consumo humano (Costa 1898; Fernández 1992: 65).

\section{Una contrastación etnográfica en la provincia de Toledo}

Además de las evidencias arqueológicas e históricas, la etnología se constituye como la tercera herramienta para analizar de forma comparada la transcendencia del vareo en las labores de recolección. En el trabajo de investigación que uno de nosotros ha realizado en el sector occidental de la provincia de Toledo sobre el aprovechamiento de las

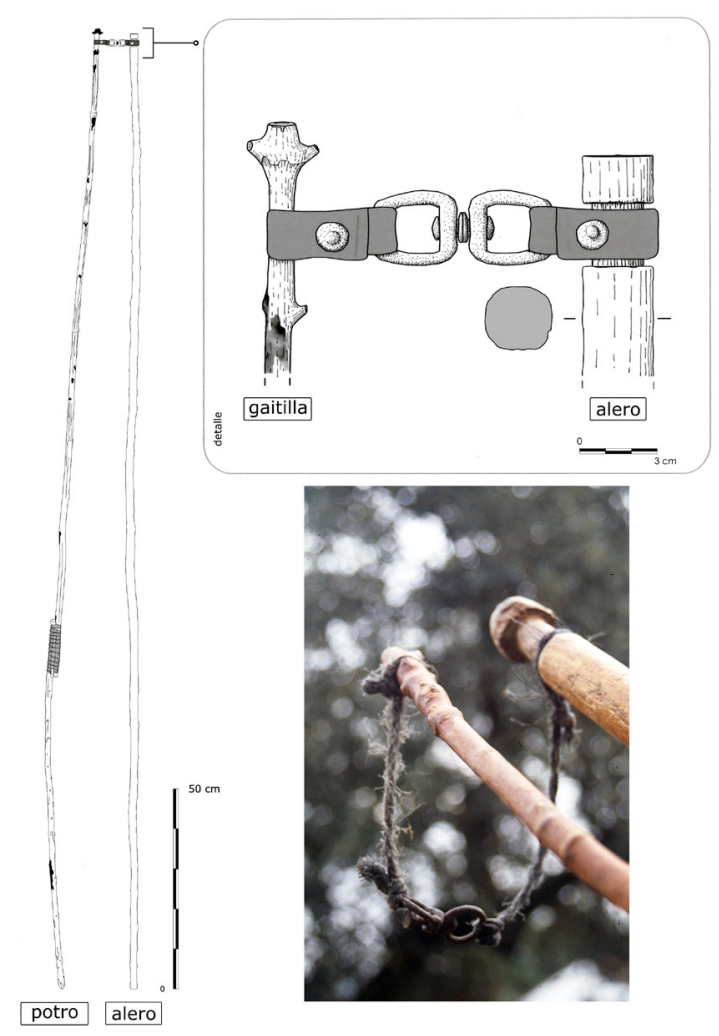

bellotas hasta la década de los 80 del siglo XX (García Gómez 2015), el instrumento utilizado para recolectar estos frutos, dependiendo de la zona, tiene nombre y composición distinta. Si bien las largas varas sencillas se seguían utilizando, en las comarcas en donde la recolección de la bellota generaba muchos jornales y mucho dinero estaban más especializados, convirtiéndose el apero de varear en un sofisticado ingenio. El $z u$ rriago, nombre con el que se denomina más habitualmente a este artefacto, consta de dos o tres palos unidos de diferentes maneras. Los más preciados constaban de tres piezas de madera (Fig. 8, Fig. 9). La medida de cada una de las piezas no era uniforme: dependía de los gustos del vareador y de la posibilidad de obtención de los distintos palos en los árboles de donde se obtienen. La más larga, que era por donde se agarra con las manos, se denomina alero (aprox. de $3 \mathrm{~m}$ ); la central, denominada gaitilla (de $1,75 / 2 \mathrm{~m})$ y la terminal o potro (de $1,25 / 2 \mathrm{~m})$.

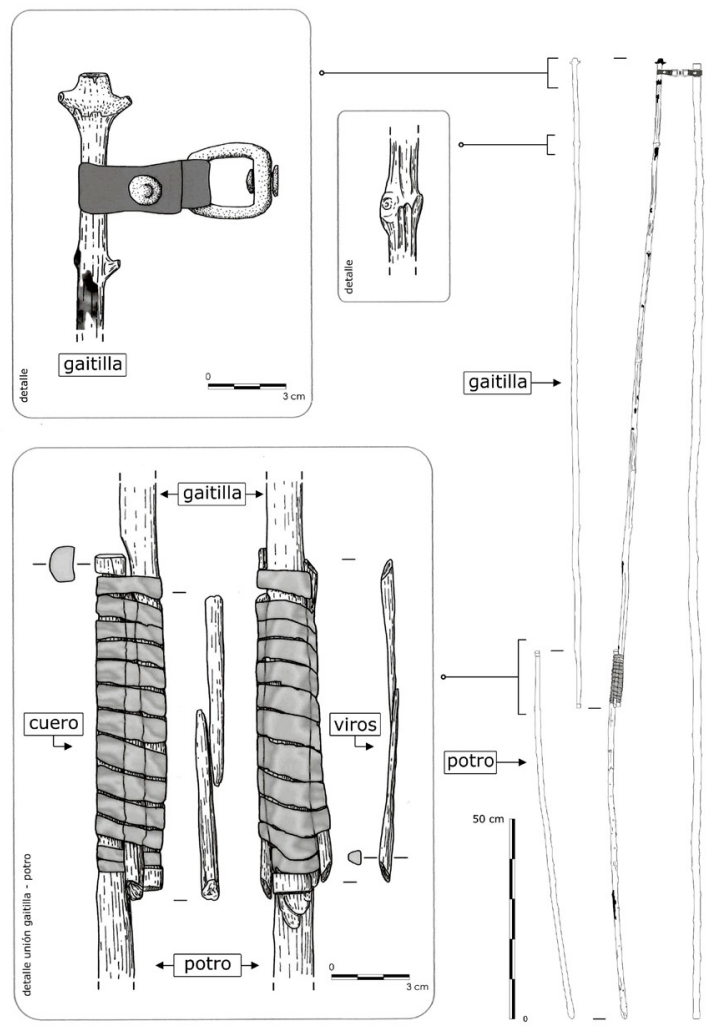

Fig. 8. Zurriago 1. Elementos y sistemas de articulación y ensamblaje de un ejemplar de Parrillas (Toledo)

Cada elemento del zurriago debía tener unas características específicas. Mientras que el alero debía ser fuerte, y a la vez ligero, la gaitilla debía permitir una cierta flexibilidad, y el potro -que era el que golpeaba a las ramillas y tenía menor longitud y grosor- debía ser rígido y resistente. Así pues, los vareadores debían mostrar un gran conocimiento de su 
entorno vegetal para saber elegir las especies más adecuadas para cada uso. Incluso el mismo zurriago podía ser diferente a lo largo de la campaña. Al comienzo, con las bellotas más verdes -más duras de tirar- el potro era más delgado, para no hacer daño a las ramillas de la encina. Cuando las bellotas estaban maduras y caían más fácilmente se cambiaba el potro por otro más grueso.

Las principales especies leñosas utilizadas para la obtención de las diferentes partes de los zurriagos eran:

\begin{tabular}{|l|l|l|}
\hline \multicolumn{1}{|c|}{ ALERO } & \multicolumn{1}{c|}{ GAITILLA } & \multicolumn{1}{c|}{ POTRO } \\
\hline Ulmus minor & Quercus ilex subsp. ballota & Quercus ilex subsp. ballota \\
Pinus spp. & Olea europea var. sylvestris & Fraxinus angustifolia \\
Populus spp. & Fraxinus angustifolia & Pistacia terebinthus \\
Ulmus minor & Prunus dulcis & Olea europea var. sylvestris \\
Alnus glutinosa & Prunus dulcis \\
Fraxinus angustifolia & Cydonia oblonga & Ulmus minor \\
& Pistacia terebinthus & \\
& Ulmus minor & \\
& Quercus pyrenaica & \\
\hline
\end{tabular}

La unión entre el alero y la gaitilla era mediante un correón o trozo de cuero, pero prácticamente casi todos los construidos durante la segunda mitad del siglo XX se unían con dos anillas metálicas que permitían el giro en todas las direcciones. Cuando aparecieron las cuerdas de plástico también se realizaron algunas uniones con ese material, ya que era barato, fácil de manejar, duradero y permitía cualquier tipo de giro. Para este uso tan específico, antes de la aparición de las anillas y de las fibras de plástico, también se utilizaba un material muy concreto: correa de piel de la mano de toro.

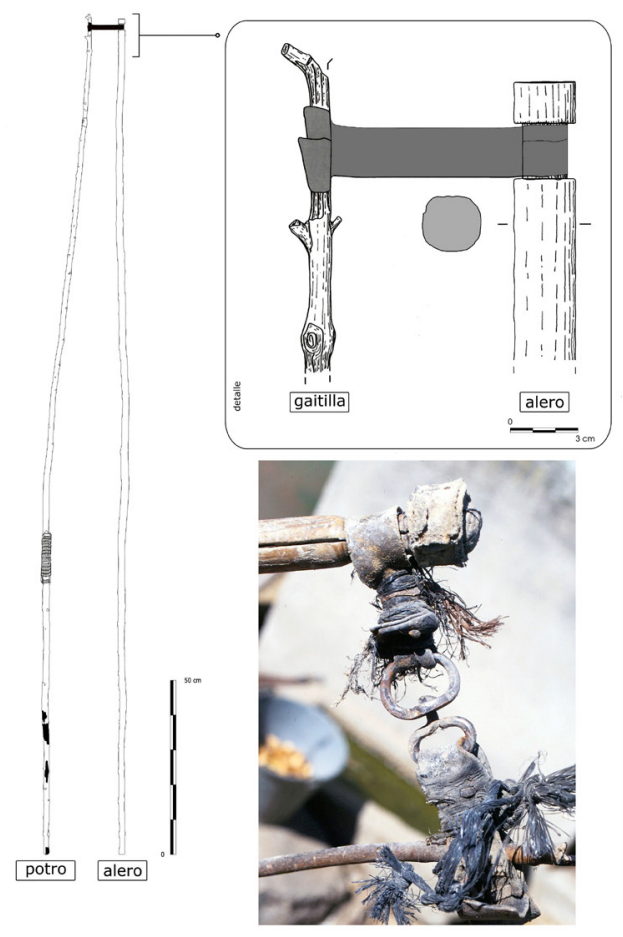

La unión entre gaitilla y potro se ha hecho siempre con un trozo de cuero, de forma que aparentemente conforman un único palo (Fig. 9). En algunos casos era de piel de burro, en otros de perro, en otros de vaca e incluso a veces era de jabalí. En muchas ocasiones estos cueros estaban engrasados. Para conseguir que la unión fuese lo mejor y más duradera, entre los palos y la tira de cuero se metían a presión unas cuñas denominadas viros, cuya misión era apretar lo más posible. Estas cuñas solían ser de jara pringosa (Cistus ladanifer) o sauces (Salix ssp.).

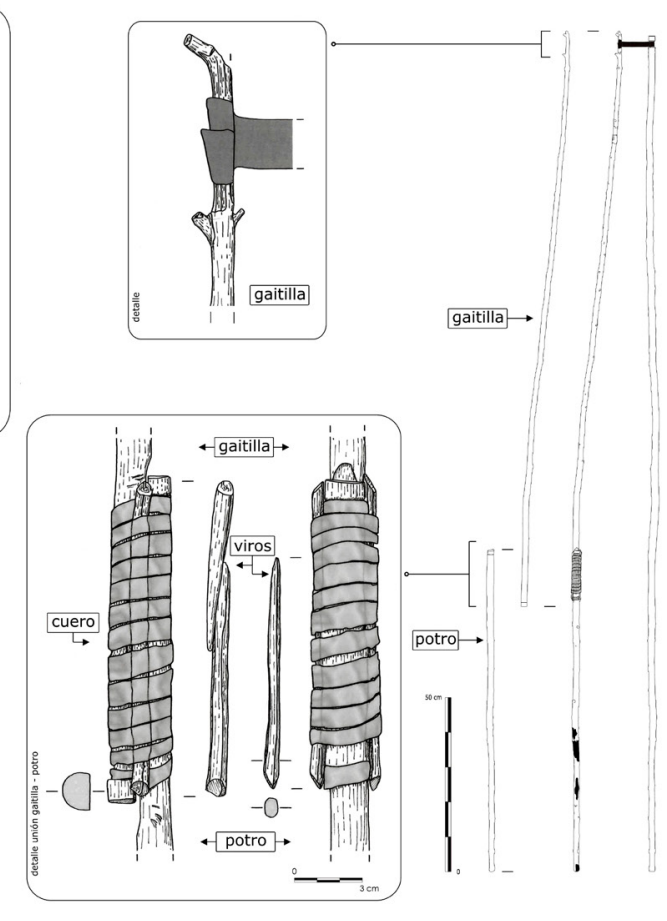

Fig. 9. Zurriago 2. Elementos y sistemas de articulación y ensamblaje de un ejemplar de Parrillas (Toledo) 
El trabajo de recolección de las bellotas estaba organizado en cuadrillas. Estas estaban integradas por varios hombres que manejaban los zurriagos, un niño o adolescente con una vara pequeña y un grupo de mujeres encargadas de recoger las bellotas que caían al suelo después del vareo. Mientras los hombres "vareadores" sacudían las ramas del perímetro de las encinas con los "zurriagos", el niño o el adolescente "picotero" trepaba por el árbol para sacudir las bellotas del interior de la copa con una vara más pequeña. La tarea concluía con la recogida de las bellotas por parte de las mujeres "recogeoras", que utilizaban cestas de mimbre con un asa vertical (Fig. 10). Esta organización de las tareas y los elementos empleados reproduce la misma imagen que hemos reseñado para el ánfora de Vulci (Fig. 5) y el libro de horas del museo Morgan (Fig. 7).

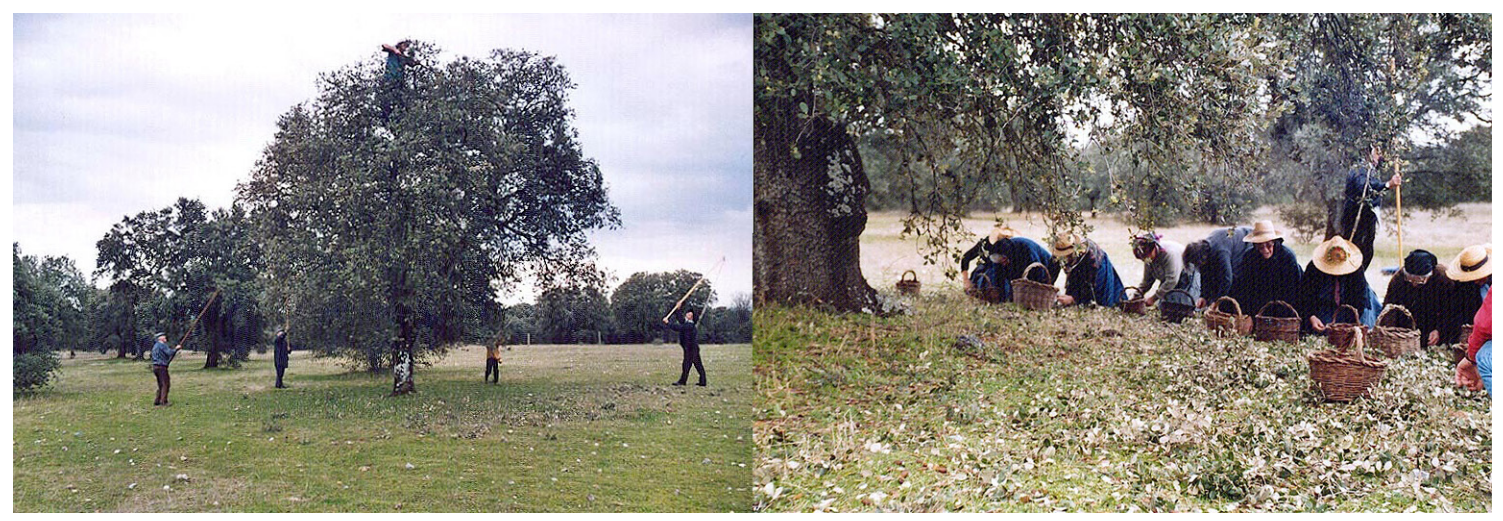

Fig. 10. Recolección de bellotas y vareo de una encina en la dehesa de Parrillas (Toledo). 1998.

Vareadores, picotero y recogeoras. Obsérvese alrededor del árbol la orla de ramillas y hojas tronchadas por el vareo.

\section{Conclusiones}

A pesar de los cambios que supuso la agricultura en la producción, gestión y consumo de los recursos alimenticios para las comunidades neolíticas del continente europeo, la recolección de vegetales silvestres se mantuvo como una estrategia más para completar la dieta de las poblaciones. Si bien desde el comienzo del Neolítico se considera que la recolección pierde importancia en las actividades de las comunidades campesinas, los hallazgos de frutos silvestres en yacimientos arqueológicos del sur y suroeste de Europa permiten proponer que una serie de especies vegetales silvestres fueron, en cierto modo, protegidas y cuidadas para ser utilizadas por estas comunidades: "La gran cantidad de restos de plantas silvestres descubiertos en las excavaciones es significativa e indica que largo tiempo después del establecimiento total de las prácticas agricolas la recolección de frutos silvestres se mantuvo en una proporción importante dentro del volumen de producción de alimentos" (Zohary y Hopf 1988: 195).

La importancia de la aportación de los recursos silvestres a la economía neolítica de la península ibérica se ve refrendada en las pinturas de La Sarga y Roca Benedí, donde se representa el vareo como una de las técnicas habituales en la recolección de los frutos de especies arbóreas autóctonas. Las condiciones del bosque mediterráneo en la península ibérica, en el que destacan las frondosas del género Quercus, podrían ser uno de los factores que explicaría la elección de las comunidades campesinas para determinados territorios de un modelo de gestión del territorio que se ha denominado agroforestal (Díaz del Río 1995). Dicho modelo implica un uso de la tierra donde las plantas leñosas -árboles y arbustos- crecen en la misma unidad de suelo en donde se realiza la explotación agrícola y ganadera. Este aprovechamiento permite el acceso tanto a recursos vegetales cultivados como silvestres, lo que concede a la comunidad un mayor componente de seguridad en el suministro para necesidades básicas.

La racionalidad económica de este tipo de gestión del entorno, mediante la adopción de una estrategia diversificadora y de pluriactividad, pretende solucionar el problema de la incertidumbre del abastecimiento anual derivada de una naturaleza 
imprevisible, que puede afectar de manera radical a las cosechas (Domínguez Martín 1992). En el caso del Neolítico Antiguo y Medio del noreste peninsular, se propone en los últimos trabajos sobre 28 yacimientos y unos 200 contextos arqueológicos estudiados (Antolín 2016: 64, fig. 3) que las bellotas se aprovecharían no como un recurso de emergencia, sino como un elemento principal de la dieta (Antolín y Jacomet 2015: 30).

Las numerosas evidencias de restos de bellotas documentadas en distintos contextos del registro arqueológico peninsular desde el Neolítico hasta la Edad del Hierro nos confirman que la recolección de bellotas tuvo un papel importante en la economía agroforestal de las comunidades campesinas de la península ibérica (Pereira y García Gómez 2002). Durante la Protohistoria el consumo de bellotas por los pueblos prerromanos peninsulares mantenía una especial relevancia, lo que hizo que fuese considerada una manifestación cultural digna de ser mencionada por autores clásicos como Estrabón o Plinio. Las evidencias documentadas en distintos yacimientos de la Edad del Hierro permiten reconstruir todos los procesos vinculados al consumo de las bellotas por las comunidades prerromanas: recolección, almacenaje, triturado, molienda, cocinado y consumo (Pereira 2010: 279). Sin embargo, las características de los elementos materiales utilizados en la recolección hacen que tengan que darse unas condiciones excepcionales para su localización e interpretación en el registro arqueológico. Solo en muy contadas ocasiones se puede refrendar la recogida masiva de bellotas en un corto periodo de tiempo (Vázquez et al. 2004: 431-432). Debemos recurrir de nuevo a la iconografía para constatar la utilización del vareo.

El ejemplo del ánfora de Antímenes es paradigmático, al mostrar las distintas actividades, organización y elementos empleados en la obtención de una cosecha de frutos mediante el vareo. La técnica pervive, independientemente del carácter cultivado o silvestre de la cosecha. La semejanza entre la imagen del ánfora de Vulci y la representada en el libro de horas del Museo Morgan es tal, que lleva a sospechar si los autores del libro de horas no conocerían la imagen griega. Los datos del Museo Británico in- dican que el ánfora de Vulci perteneció a Luciano Bonaparte, príncipe de Canino, localidad cercana al yacimiento, que proporcionó una parte importante de su conocida colección de antigüedades. El ánfora de Antímenes fue adquirida por el Museo Británico en 1837, por lo que resulta poco probable que fuera conocida en el siglo XV. La gran semejanza entre las dos imágenes permite comprobar la pervivencia durante 15 siglos de un sistema de recolección mediante vareo sin ningún tipo de variación significativa.

Por último, el trabajo del vareo y recolección representados en las imágenes reseñadas mantendrán su pervivencia, según hemos constatado, en las técnicas usadas por los habitantes del mundo rural para la recolección de la bellota en las dehesas del occidente peninsular. Estas técnicas se continuaban utilizando en los años 60 del siglo XX. El uso de varas se sigue manteniendo y aún en la actualidad se puede ver en distintos lugares, sobre todo vinculado a su aprovechamiento como forraje. En las zonas donde a mediados del siglo XX se mantenía como una actividad organizada se ha constatado el desarrollo de una herramienta algo más compleja, compuesto de varias partes, como es el zurriago. Por otro lado, la organización y distribución de tareas son muy semejantes a los usados, por lo menos, desde el primer milenio a. C, como en el caso del "picotero" con una pequeña vara recta que trabaja en la copa de la encina y las "recogeoras". Las pinturas rupestres, la iconografía del ánfora de Vulci, el libro de horas de la biblioteca Morgan y los datos etnográficos de las dehesas del centro oeste peninsular nos permiten comprobar cómo durante 2.500 años ha perdurado la misma cadena operativa entre los campesinos de la Europa mediterránea para la recolección de determinados frutos propios de los ecosistemas mediterráneos.

Al igual que en el pasado, en un futuro poco o nada quedará de los elementos utilizados para el vareo, salvo alguna pieza en un museo etnográfico, y serán de nuevo las imágenes en distintos soportes y las evidencias documentales las que proporcionarán la información sobre una técnica de aprovechamiento de los bosques de especies del género Quercus que está a punto de desaparecer. 


\section{Bibliografía}

Alonso, N.; Pérez, G.; Rovira, N.; López, D. (20169: "Gathering and consumption of wild fruits in the east of the Iberian Peninsula from the 3rd to the 1st millennium BC". Quaternary International.Vol. 404. Part.A, 6 June 2016, 69-85.

Antolín, F. (2015): "Entre agricultores primitivos, cultivos de rozas y pastores trashumantes. Una mirada crítica a los modelos económicos propuestos para los grupos neolíticos del noreste peninsular y una aportación desde el registro carpológico". Revista d'Arqueologia de Ponent. 25. 11-45.

Antolín F. (2016): Local, intensive, and diverse? Early farmers and plant economy, in the North-East of the Iberian Peninsula (5500-2300 cal BC). Barkhuis Publishing. Groningen.

Antolín, F. y Jacomet S. (2015): "Wild fruit use among early farmers in the Neolithic (5400-2300 cal. BC) in the north-east of the Iberian Peninsula: an intensive practice?". Vegetation, History and Archaeobotany. 24.19-33.

Aurenche, O. (1997): Balanophagie: mythe ou réalité?. Paléorient, 23/1: 75-85.

Ayala, M. M. (1987): "Enterramientos calcolíticos de la Sierra de la tercia. Lorca. Murcia. Estudio preliminar". Anales de Prehistoria y Arqueología, 3: 9-24.

Beazley, J. D. (1986): The development of Attic-Black Figures. University of California Press. Berkeley.

Blasco, C. (1997): "Manifestaciones funerarias de la Edad del Bronce en la Meseta". SAGUNTUM, 30: 173190.

Book of hours of the Virgin (ca 1430) The Morgan Library MS. M64 fol.11 v.

Bueno, P.; Balbín, R. y Barroso, R. (2004): "Vida y muerte en los grupos megalíticos del interior de la Península Ibérica. La Cuenca del Tajo como modelo". Cuadernos de Arqueología Universidad de Navarra. 12: 5177.

Bueno, P.; Barroso, R.; Balbín, R.; Campo, M.; González, A.; Etxeberría, F.; Herrasti, L.; Galván, V.; JuanTreserras, J.; López, J. A.; López, P.; Matamala, J.C.; Millos, J. J.; Robledo, B.; Trancho, G. y Sánchez, B. (2005): “Alimentación y economía en contextos habitacionales y funerarios del Neolítico meseteño". En P. Arias, R. Ontañón y C. García-Moncó. (eds.). Actas del III Congreso del Neolítico en la Península Ibérica. Santander. Universidad de Cantabria: 83-92.

Buxó, R. (1987): “Adopción de la agricultura en el Nordeste de Cataluña”. Revista de Arqueología, 80.

Buxó, R. (1997): Arqueología de las Plantas. Edit. Crítica. Barcelona.

Buxó, R. y Piqué R. (2008): Arqueobotánica. El uso de las plantas en la Península Ibérica. Ariel. Barcelona.

Camarero, C. (2002): "El Catastro de Ensenada, 1749-1759: diez años de intenso trabajo y 80.000 volúmenes manuscritos". Catastro.46: 61-88.

Campos J. (2003): "Las Relaciones Topográficas de Felipe II: Índices, Fuentes y Bibliografía”, Anuario Jurídico y Económico Escurialense, XXXVI: 439-574.

Costa, J. (1898): Colectivismo agrario en España. Madrid.

Herrera, A. (1996): Agricultura General 1513. Facsimil. Ministerio de Agricultura. Madrid.

Díaz del Río Español, P. (1995): "Campesinado y gestión pluriactiva del ecosistema: un marco teórico para el análisis del III y II milenios a. C. en la Meseta peninsular”. Trabajos de Prehistoria. 52 (2): 99-109.

Domínguez Martín, R. (1992): “Campesinos, mercado y adaptación. Una propuesta de síntesis e interpretación desde una perspectiva interdisciplinar". Noticiario de Historia Agraria. 3. Murcia: 91-130.

Fernández Montes, M. (1992): "Los aprovechamientos comunales del monte en el cuadrante Noroocidental de España". Anales del Museo del Pueblo Español. T. IV. Ministerio de Cultura. Madrid: 49-83.

Font Quer, P. (1954): “La vegetación”. En M. Terán (Dir.). Geografia de España y Portugal. T. II. Barcelona.

Fortea, J. y Aura Tortosa, J. E. (1987): "Una escena de vareo en La Sarga (Alcoy). Aportaciones a los problemas del Arte Levantino". Archivo de Prehistoria Levantina. XVII: 97-122.

García Gómez, E. (2015): Estudio etnobotánico y etnográfico en relación a los frutos de las diferentes especies del género Quercus (fagáceas) en la península ibérica. Tesis Doctoral. Universidad de CastillaLa Mancha.

García Gómez, E.; Pereira, J. y Ruiz Taboada, A, (2002): “Aportaciones al uso de la bellota como recurso alimenticio por las comunidades campesinas". Cuadernos de la Sociedad Española de Ciencias Forestales, 14: 65-70.

García Gómez, E.; Pereira, J. y Vizuete J.C. (2003): "El Monte mediterráneo como paisaje cultural desde una perspectiva interdisciplinar". Actas II Reunión de Historia Forestal. Cuadernos de la Sociedad Española de Ciencias Forestales. 16: 11-18. 
García y Bellido, A. (1978): La España del siglo I de nuestra era. Colección Austral. 744. Espasa-Calpe. Madrid.

Gómez Barrera, J. (2005): “La pintura rupestre esquemática como acción social de los grupos ganaderos en la meseta castellano leonesa". Cuadernos de Arte Rupestre, 2: 11-58.

Heizer, R. F. (1978): Handbook of North American Indians. Vol. 8. Smithsonian Institution. Washington: 1624.

Hernández Pérez, M. y Martí Oliver, B. (2000-1): "El arte rupestre de la fachada mediterránea: entre la tradición epipaleolítica y la expansión neolítica”. Zephyrus. 53-54: 241-256.

Hernández Pérez, M.; Ferre i Marset, P. y Catalá, E. (2002): "La Sarga (Alcoy, Alicante). Catálogo de pinturas y horizontes artísticos". En M. Hernández y J. Segura (coord.) La Sarga. Arte rupestre y territorio. Edit. Ayto. Alcoy y CAM: 51-100.

Lapena F. R. (1978): "Wintu”. En R.F. Heizer (ed.) Handbook of North American Indians. Vol. 8. Smithsonian Institution. Washington: 324-340.

Levy R. (1978 a): "Eastern Miwok". En R.F. Heizer (ed.): Handbook of North American Indians. Vol. 8. Smithsonian Institution. Washington: 398-413.

(1978 b): "Costanoan". En R.F. Heizer (ed.): Handbook of North American Indians. Vol. 8. Smithsonian Institution. Washington: 485-495.

López García, P, y Molero, G. (1984): “Análisis de los restos vegetales, faunísticos y polínicos del yacimiento de La Sarsa (Bocairente, Valencia)". Trabajos de Prehistoria. Vol. 41. Madrid.

López Sáez, J.A.; López García, P.; López Merino, L.; Cerrillo Cuenca, E.; González Cordero, A. y Prada Gallardo, A. (2007): "Origen prehistórico de la dehesa en Extremadura: una perspectiva paleoambiental" Revista de Estudios Extremeños. 63,1: 493-510.

Madoz, P (1987): Diccionario geográfico-estadístico-histórico de España y sus posesiones de ultramar. Domingo Sánchez Zurro (Ed.) sobre la edición facsimilar de Madrid, 1845-1850.Valladolid, Ámbito Ediciones; Junta de Comunidades de Castilla-La Mancha.

Martí, B. y Juan-Cabanilles, J. (1987): El Neolític valenciá. Els primers agricultors i ramaders. Valencia.

Martín Colliga, A. (1992): "La economía de producción a lo largo del Neolítico en Cataluña". Elefantes, ciervos y ovicápridos. Universidad de Cantabria: 203-229.

Martín Socas, D.; Camalich, M. D. y González Quintero, P. (1987): "Informe preliminar de la campaña de 1985 en la Cueva del Toro de El Torcal (Antequera)". Anuario Arqueológico Andalucía. Vol. II Actividades sistemáticas. Junta de Andalucía: 233-240.

Mason, S. L. (1992): Acorns in Human subsistence. Doctoral Tesis. Institute of Archaeology, University College. London.

Miranda García, C. (2001): Iconografia del "Breviari d'amor": Escorial, Ms, SI n³, Madrid Biblioteca Nacional Ms, Rs 203. Universidad Complutense. Madrid.

Molina Balaguer, L. L.; García Puchol, O. y García Robles M. R. (2003): Apuntes al marco crono-cultural del arte levantino: Neolítico vs neolitización. Saguntum, 35: 35-67.

Molist, M. y Clop, X. (2000): "La investigación sobre el megalitismo en el Noroeste de la Península Ibérica: novedades y perspectivas". Trabalhos de Arqueología, 16: 253-266.

Montero Riquelme, F. J. (1993): Caracterización morfológica del almendro. Servicio de Publicaciones de la Universidad de Castilla-La Mancha. Cuenca.

Moure, A. (1992): "Economía y aprovechamiento del medio en la Prehistoria de España y Portugal”. Elefantes, ciervos y ovicápridos. Universidad de Cantabria: 9-16.

Muñoz, A. M. (1970): “Estado actual de la investigación sobre el Neolítico español”. Pyrenae. Vol. VI: 13-28.

Pellicer, M. (1962): Estratigrafia prehistórica de la Cueva de Nerja. Excavaciones Arqueológicas en España. $\mathrm{N}^{\mathrm{o}} 16$. Madrid.

Pereira, J. (2010): "Paleoetnografía del consumo de bellotas en las comunidades prerromanas peninsulares". Arqueología, sociedad, territorio y paisaje. Bibliotheca Prehistórica Hispana Vol. XXVIII: 279-290.

Pereira, J. y García Gómez, E. (2002): "Bellotas el alimento de la Edad de Oro". Arqueoweb 4 (2) Octubre.

Pérez Jordá, G. (2005): "Nuevos datos paleocarpológicos en niveles neolíticos del País Valenciano". En E. P.Arias, R. Ontañón y C. García Monco (ed.). Actas del II Congreso del Neolítico en la Península Ibérica. Santander. Universidad de Cantabria: 73-81.

Pérez Jordà, G.; Peña-Chocarro, L.; García Fernández, M.; Vera Rodríguez, J.C. (2017): "The beginnings of fruit tree cultivation in the Iberian Peninsula: plant remains from the city of Huelva (southern Spain)". Vegetation History and Archaeobotany 26: 527-538. 
Powers, S. (1874). “Aboriginal botany”. Proceedings of the California Academy of Sciences, 5: 373-379.

Rodríguez, A. y Ortiz P. (2004): "La Mata, un edificio organizado". En Rodríguez, A. (Ed.) El edificio protohistórico de "La Mata" (Campanario, Badajoz) y su estudio territorial. Vol. I. Universidad de Extremadura. Cáceres: 75-312.

Rojo-Guerra, M. A. y Kunst M. (1999): "La Peña de la Abuela. Un enterramiento neolítico sellado por la acción del fuego". Revista de Arqueología, 220: 12-19.

Ruas, M.P. y Bouby, L. (2010): “Carbonization, conservation et deformation des restes carpologiques” P@ lethnologie.2: 69-79.

Sanz, C.; Velasco, J. y Centeno, I. (2003): “La necrópolis tardoantigua e hispanovisigoda de Las Quintanas". En Sanz, C. y Velasco, J. (ed.). Pintia. Un oppidum en los confines orientales de la región vaccea. Investigaciones arqueológicas Vacceas, Romanas y Visigodas (1999-2003). Universidad de Valladolid: 221-247.

Senna-Martínez, J. C. (1994): "Megalitismo, habitat e sociedades: a bacia do medio e Alto Mondego no conjunto da Beira Alta (5.200-3000 BP)". O megalitismo no centro de Portugal. Mangualde-Viseu: $15-29$.

Ureña, R (2003): Fuero de Cuenca. Real Academia de la Historia, Madrid 1935. Facsímil. Universidad de Castilla-La Mancha.

Utrilla, P.; Bea, M. y Benedí, M. (2010): "Hacia el Lejano Oeste. Arte Levantino en el acceso a la Meseta: la Roca Benedí (Jaraba, Zaragoza, España)”. Trabajos de Prehistoria. 67.1: 227-243.

Vázquez, F.; Ramos, S.; Doncel, E. y Pérez, G. (2004): "La recolección de bellotas, aspectos de su procesado y caracterización". En Rodríguez, A. (ed.). El edificio protohistórico de "La Mata" (Campanario, Badajoz) y su estudio territorial. Vol. I. Universidad de Extremadura. Cáceres: 423-432.

Vicent, A.M. y Muñoz, A.M. (1977): $2^{a}$ Campaña de excavaciones en la Cueva de Los Murciélagos 1969. Excavaciones Arqueológicas en España.

Zapata, L. (2000): La recolección de plantas silvestres en la subsistencia mesolítico y neolítica: Datos arqueobotánicos del País Vasco. Complutum. 11: 157-169.

Zapata, L.; Baldellou, V. y Utrilla, P. (2008): "Bellotas de cronología neolítica para consumo humano en la Cueva de Chaves (Bastarás,Huesca)". En M. Hernández, J. Soler y J. A. López Padilla (ed.). IV Congreso del Neolítico Peninsular. Vol. I: 402-410.

Zohary, D. y Hopf, M. (1988): Domestication of Plants in the Old World. $1^{\text {a }}$ ed. Oxford. Clarendon Press. 